\title{
SECOND LARGEST GROWING NEW PRODUCT
}

Dentisan is delighted with the recent release of figures from the British Dental Trade Association (BDTA), showing that Bioclear, their biofilm remover for dental unit water lines which is manufactured at their Derbybased headquarters, was the second largest growing new product launched to the profession in 2011, and the only one in the top ten from the infection control sector.

The figures released annually by the BDTA are compiled by Strategic Data Marketing, and show that water treatment solutions enjoyed year-onyear growth of more than 38\% during 2011-2012.

Greater awareness of the problem of biofilm in dental unit water lines has been one of Dentisan's key objectives over the last two years, and now knowledge amongst the profession is good. A recent survey showed that $98 \%$ of dentists were aware of the problem of biofilm in relation to dental unit water line contamination.

For more information visit www. dentisan.co.uk.

\section{NINE CONVENTIONAL INSTRUMENTS IN ONE}

Unveiled for the first time at the Cologne IDS show, Deppeler Smart Scaling is a pioneering periodontal instrument kit. Designed for maximum efficiency, its angulation and ergonomic features allow it to do the work of up to nine conventional instruments and provide much better access to periodontal pockets. This innovative new system also offers practitioners significant improvements in their day-to-day working comfort.

Deppeler Smart Scaling, like all Deppeler products, has been designed to make periodontal treatments easier and more effective. Developed with the needs of dental professionals in mind, it is the result of careful and considered research into the shape, angulations, thickness and contour of the blade, and aims to provide maximum comfort for both practitioners and patients.

The depth of the pocket is also critical in periodontal procedures, and Deppeler Smart Scaling is the first instrument system to allow practitioners to observe the depth of periodontal pockets throughout the descaling process.

The Deppeler Smart Scaling system is designed to simplify professional practices, opening up new possibilities in periodontal treatments and streamlining procedures by minimising the number of instruments required. www.deppeler.ch

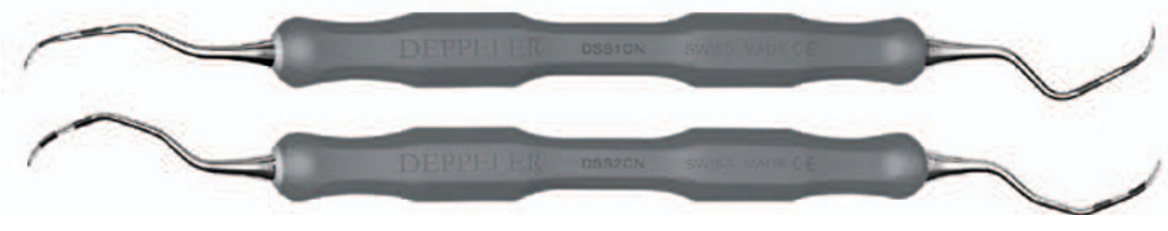

\section{FREE MARKETING SEMINARS}

Denplan has launched a series of marketing seminars to help its members grow patient numbers.

'Getting to Grips with Patient Growth' seminars are designed to help member dentists with patient recruitment and ongoing practice profitability. They are provided in 17 locations around the UK and each event will provide members helpful tips on: growing their patient base and increasing patient loyalty; marketing advice to increase awareness of their practice locally; using local media to gain publicity and awareness of their practice; basics of social media and building an online presence; and how business planning and consultancy can increase your patient numbers.

The seminars are free for Denplan members; for more information see www.denplan.co.uk/patientgrowth. 